\title{
Cancer Antigen-125 is Specifically Associated with Ascites and has no Relation with Liver Function in Liver Cirrhosis
}

Mohammed Ali Chowdhury, Xiubin Zhang, Wei Han

\begin{abstract}
Background: Cancer antigen-125 (CA-125) is a high molecular weight glycoprotein used as a marker for ovarian carcinoma. But its involvement is also observed in many benign conditions particularly in liver cirrhosis and ascites. However, the reason behind it remains unclear.
\end{abstract}

Materials and methods: A total of 53 patients with liver cirrhosis, Budd-Chiari syndrome and tuberculous peritonitis were enrolled in this study. The degree of ascites was graded to into mild, moderate and severe. CA-125 levels of all the patients were measured along with other liver parameters.

Results: No association was observed between CA-125 levels of liver cirrhosis patients and parameters of liver function tests. All the patients with ascites had elevated level of CA-125, whereas most of the patients without ascites had CA- 125 levels under the normal range. However, the levels of CA-125 were significantly higher in patients with ascites compared to patients without ascites $(p<0.05)$.

Conclusion: The elevation of CA-125 in liver cirrhosis may be related to ascites and not dependent on parameters of liver dysfunction. Therefore, CA-125 may be used as a predictor of ascites in patients with liver cirrhosis.

Keywords: CA-125, Liver cirrhosis, Ascites.

How to cite this article: Chowdhury MA, Zhang X, Han W. Cancer Antigen-125 is Specifically Associated with Ascites and has no Relation with Liver Function in Liver Cirrhosis. Euroasian J Hepato-Gastroenterol 2013;3(2):108-110.

Source of support: Nil

Conflict of interest: None

\section{INTRODUCTION}

Cancer antigen-125 (CA-125) is a glycoprotein with high molecular weight which can be recognized by monoclonal antibody (OC-125), raised from ovarian carcinoma cell line. ${ }^{1}$ CA-125 is widely applied as marker in ovarian carcinoma but its sensitivity and specificity both may be elusive. $.^{2-5} \mathrm{CA}-125$ is known to be produced by tissues of celomic epithelium origin. ${ }^{6}$ Several studies have showed CA-125 elevation in nonmalignant conditions like pelvic inflammatory disease and endometriosis, ${ }^{7-9}$ more recently Miralles et al and Turk et al showed elevated CA-125 even in benign conditions like heart failure. ${ }^{10,11}$ In particular, strong elevation of CA-125 is observed in liver cirrhosis. ${ }^{12-15}$ However, it is not well understood if CA-125 elevation is related to liver dysfunction or ascites.

The aim of the present study is to (1) to describe the relationship of CA-125 with liver function in liver cirrhosis,
(2) to describe relationship of CA-125 and ascites, and (3) to find if CA-125 elevation is associated with any particular etiology of liver cirrhosis and other diseases.

\section{MATERIALS AND METHODS}

A total of 53 patients (37 males and 16 females), aged between 17 and 81 years (mean age: $53.28 \pm 17.57$ years) diagnosed with liver cirrhosis, Budd-Chiari syndrome and tuberculosis peritonitis were enrolled in this study who were admitted in our department between January 2010 and September 2012. The study was approved by the local ethical committees and conducted in accordance with the Declaration of Helsinki. Patients with any malignant condition including ovarian carcinoma were excluded from the study. All patients were subdivided into two groups according to the presence and absence of ascites. Final distribution of the patients were as follows: (1) liver cirrhosis patients with ascites; $n=23$, without ascites; $n=12$, BuddChiari syndrome patients with ascites; $n=5$, without ascites; $\mathrm{n}=5$ and tuberculosis peritonitis patients with ascites; $\mathrm{n}=8$. The diagnosis of ascites was confirmed by physical examination followed by ultrasonography and computed tomography. The amount of ascites was graded according into mild, moderate and severe. Venous blood samples were collected to measure serum CA-125 and for evaluating liver function parameters.

CA-125 measurements were performed through Elecsys CA-125 || CalSet (Roche, Switzerland) on an Elecsys 2010 (Roche, Rotkreuz, Switzerland) immunoassay system using monoclonal antibodies. The sandwich principle was followed and the complex was incubated. In the measuring cell the microparticles are captured by the magnets into the surface of the electrodes and voltage is induced into the electrodes for chemiluminescent emission which is measured by a photomultiplier. Results are obtained via a calibration curve which is instrument specific and generated by 2-point calibration and a master curve provided via the reagent barcode. A value of $>35 \mathrm{U} / \mathrm{ml}$ was considered above the upper limit of normal.

Albumin, total bilirubin, cholesterol, gamma-glutamyl transferase, alanine aminotransferase and aspartate transaminase were measured using Cobas 8000 automatic biochemical analyzer and reagent (Roche, Rotkreuz, Switzerland) along with prothrombin-INR which was measured with ACL 9000 automatic coagulation analyzer and reagent (Instrumentation Laboratory, Italy). 
Statistical analysis was done by the computer program SPSS (version 20). Mean, standard deviation, independent and dependent two-tailed t-test, Spearman's correlation coefficient was calculated for evaluating the significance of CA-125 in all groups and to evaluate the relationship of CA-125 with degree of ascites and other liver parameters. A $\mathrm{p}$-value less than $0.05(\mathrm{p}<0.05)$ was considered statistically significant.

\section{RESULTS}

In this study CA-125 was seen to have a high specificity and sensitivity (specificity: $87.5 \%$, sensitivity: $96.5 \%$ ) as a marker for ascites. When CA-125 levels of liver cirrhosis patients were correlated with liver function parameters no significant correlation was observed. However, when CA-125 level was correlated with degree of ascites a significant correlation $\mathrm{p}<0.05$ was seen (Table 1 ).

Table 1: Correlation of CA-125 levels with liver function parameters and degree of ascites in liver cirrhosis patients

\begin{tabular}{l|l|l|}
\hline Albumin & 0.316711 & 0.063785 \\
\hline Total bilirubin & 0.315236 & 0.065099 \\
\hline Prothrombin time INR & 0.271153 & 0.115121 \\
\hline Gamma-glutamyl transferase & 0.270384 & 0.116196 \\
\hline Cholesterol & 0.231685 & 0.180507 \\
\hline Alanine aminotransferase & 0.182901 & 0.292953 \\
\hline Aspartate transaminase & 0.176479 & 0.310519 \\
\hline Degree of ascites & 0.770378 & $0.000000^{*}$ \\
\hline
\end{tabular}

"Significance seen at 0.05 level, $r=$ Spearman's correlation coefficient, $p=$ correlation coefficient significance

The levels of CA-125 in patients with liver cirrhosis and ascites $(247.11 \pm 118.15 \mathrm{U} / \mathrm{ml})$ were significantly higher than in patients with liver cirrhosis without ascites $(9.18 \pm$ $4.46 \mathrm{U} / \mathrm{ml})(\mathrm{p}<0.05)$.

As shown in Graph 1, the levels of CA-125 showed progressive increase with degree of ascites in patients with liver cirrhosis $(\mathrm{p}<0.05)$.

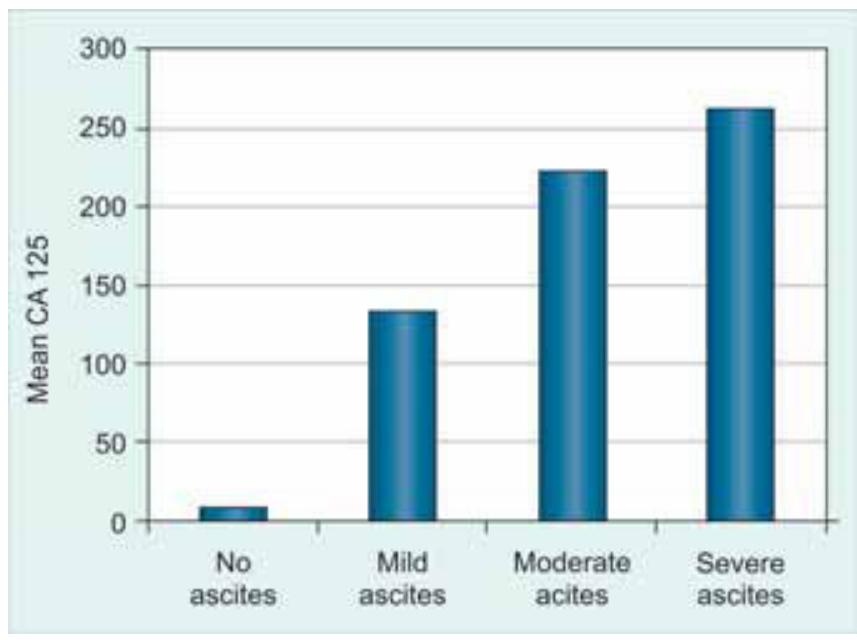

Graph 1: The bar diagram shows the correlation between CA125 levels and degree of ascites in all patient
All the patients with ascites had elevated level of CA-125 whereas all the patients without ascites had CA-125 levels under the normal range. The highest elevation was seen in case of liver cirrhosis patients with ascites. But, when ascitic patients with different diseases were compared no significant difference among patients with different etiologies of ascites $(p>0.05)$ was observed.

\section{DISCUSSION}

Maximum elevations of CA-125 are seen in case of liver diseases specifically liver cirrhosis. ${ }^{16,17}$ In this study, we did not find any correlation between CA-125 and liver function in liver cirrhosis patients unlike Devarbhavi and Collazos who found good correlation and suggested that CA-125 elevation in liver cirrhosis is due to liver dysfunction. . $^{15,17,18}$ Albumin, bilirubin, prothrombin time have been considered as good indicator of liver function ${ }^{19}$ and was used in this study to assess liver function among the patients.

In our study, we observed elevated CA-125 in all liver cirrhosis patients with ascites and most liver cirrhosis patients without ascites had CA-125 level under the normal range unlike previous studies where liver cirrhosis patients without ascites had abnormal CA-125 level. ${ }^{15-17,20}$ We also observed strong correlation between CA-125 levels and degree of ascites $(\mathrm{p}<0.05)$, similar to previous studies carried out by Zuckerman et al. . $^{13,17,21,22}$

When patients of other benign diseases like Budd-Chiari syndrome and tuberculosis peritonitis were included, a similar observation was seen for patients with ascites which further support our claim of CA-125 being a marker of ascites and that CA-125 elevation is not associated with any particular etiology of diseases.

The mechanism behind the elevation of CA-125 in ascites is not well explained. Previous studies have showed elevation of CA-125 in presence of pleural fluid too but the elevation was less compared to those found in ascitic patients ${ }^{11,23}$ and possible reason behind it was assumed to be the large surface area of the peritoneum. ${ }^{24}$ Peritoneal mesothelial cells can produce CA- $125^{2,25}$ and peritoneal irritation or stress may cause excessive production of CA-125 into the circulating blood thus contributing to elevation of CA-125 levels. ${ }^{26}$ We assume that in ascites, the mesothelial cells may play a central role for elevation of CA-125 as previous studies suggested CA-125 binding to mesothelial promotes cell adhesion, ${ }^{27}$ however, this remains to be confirmed in future. There are many procedures like ultrasound and computed tomography to diagnose ascites. We think that CA-125 can be used as a tool for early diagnosis of ascites and for monitoring the prognosis of ascites as previous study by Zuckerman showed us sharped decrease in CA-125 level after successful therapy. ${ }^{13}$ In 
clinic, there are several conventional ways to treat ascites but refractive ascites still remains a difficult condition to manage as there is no efficient medical treatment for them. ${ }^{28}$ Further research is suggested in this context.

\section{ACKNOWLEDGMENTS}

Authors would like to thank all the staffs of Department of Gastroenterology, Qilu Hospital of Shandong University, for their support and all the patients involved in the study.

\section{REFERENCES}

1. Bast RC Jr, Feeney M, Lazarus H, Nadler LM, Colvin RB, Knapp RC. Reactivity of a monoclonal antibody with human ovarian carcinoma. J Clin Invest 1981 Nov;68(5):1331-1337.

2. Schrijvers D, van Dam P, van Oosterom A. CA 125: a misleading tumor marker? Int J Gynaecol Obstet 1996 Nov;55(2):179-180.

3. Jacobs I, Bast RC Jr. The CA 125 tumour-associated antigen: a review of the literature. Hum Reprod 1989 Jan;4(1):1-12.

4. Bast RC Jr, Knapp RC. Use of the CA 125 antigen in diagnosis and monitoring of ovarian carcinoma. Eur J Obstet Gynecol Reprod Biol 1985 Jun;19(6):354-356.

5. Bast RC Jr, Klug TL, St John E, Jenison E, Niloff JM, Lazarus H, Berkowitz RS, Leavitt T, Griffiths CT, Parker L, et al. A radioimmunoassay using a monoclonal antibody to monitor the course of epithelial ovarian cancer. N Engl J Med 1983 Oct;309(15):883-887.

6. Kabawat SE, Bast RC Jr, Welch WR, Knapp RC, Colvin RB. Immunopathologic characterization of a monoclonal antibody that recognizes common surface-antigens of human ovarian tumors of serous, endometroid, and clear cell types. Am J Clin Pathol 1983 Jan;79(1):98-104.

7. Halila H, Stenman UH, Seppala M. Ovarian cancer antigen CA125 levels in pelvic inflammatory disease and pregnancy. Cancer 1986 Apr;57(7):1327-1329.

8. Pittaway DE, Douglas JW. Serum CA125 in women with endometriosis and chronic pelvic pain. Fertil Steril 1989 Jan;51(1):68-70

9. Eisermann J, Collins JL. Enzyme immune assay determination of CA125 in serum, peritoneal fluid, and follicular fluid from women with minimal endometriosis after ovarian hyperstimulation. Fertil Steril 1989 Feb;51(2):344-347.

10. Miralles C, Gea T, Orea M, Espana P, Provencio M, Sanchez A, Cantos B, Cubedo R, Carcereny E, Bonilla F. Cancer antigen 125 associated with multiple benign and malignant pathologies. Ann Surg Oncol 2003 Mar;10(2):150-154.

11. Turk HM, Pekdemir H, Buyukberber S, Sevinc A, Camci C, Kocabas R, Tarakcioglu M, Buyukberber NM. Serum CA 125 levels in patients with chronic heart failure and accompanying pleural fluid. Tumour Biol 2003 Aug-Sep;24(4):172-175.

12. Bergmann JF, Bidart JM, George M, Beaugrand M, Levy VG, Bohuon C. Elevation of CA 125 in patients with benign and malignant ascites. Cancer 1987 Jan;59(2):213-217.

13. Zuckerman E, Lanir A, Sabo E, Matter I, Yeshurun D, Eldar S, Rosenvald-Zuckerman T. Cancer antigen 125: a sensitive marker of ascites in patients with liver cirrhosis. Am J Gastroenterol 1999 Jun;94(6):1613-1618.

14. Molina R, Filella X, Bruix J, Mengual P, Bosch J, Calvet X, Jo J, Ballesta AM. Cancer antigen CA125 in serum and ascitic fluid of patients with liver disease. Clinl Chem 1991 Aug;37(8):1379-1383.
15. Devarbhavi H, Kaese D, Williams AW, Rakela J, Klee GG, Kamath PS. Cancer antigen 125 in patients with chronic liver disease. Mayo Clin Proc 2002 Jun;77(6):538-541.

16. Piekarska A, Piekarski J, Zboinska J. Elevated levels of cancer antigen CA-125 in patients with chronic liver diseases, with and without ascites. Exp Clin Hepatol 2005;3:30-33.

17. Collazos J, Genolla J, Ruibal A. CA 125 serum levels in patients with non-neoplastic liver diseases. A clinical and laboratory study. Scand J Clin Lab Invest 1992 May;52(3):201-206.

18. Kim YS, Kim DY, Ryu KH, Song JH, Kim MS, Jung HS, Park JY, Jung HK, Yoo K, Moon IH, et al. Clinical significance of serum CA 125 in patients with chronic liver diseases. Korean J Gastroenterol 2003 Nov;42(5):409-414.

19. Jhonston DE. Special considerations in interpreting liver function test. Am Fam Physician 1999 Apr;59(8):2223-2230.

20. Xiao WB, Liu YL. Elevation of serum and ascites cancer antigen 125 levels in patients with liver cirrhosis. J Gastroenterol Hepatol 2003 Nov;18(11):1315-1316.

21. Xu J, Liu J, Guo JX, Ma HB, Zhao J, Liu AX, Xu WN, Li BA, Mao YL. Evaluation on clinical value of serum CA-125 in hepatitis cirrhosis. Zhonghua Shi Yan He Lin Chuang Bing Du Xue Za Zhi 2010 Oct;24(5):334-336.

22. Algan Ocal P, Aksahin A, Cetin T, Yildirim IS. Cancer antigen 125 levels in patients with ascites. Turk J Gastroenterol 2003 Dec;14(4):257-261.

23. Kalantri Y, Naik G, Joshi SP, Jain A, Phatak S, Chavan R, Hemvani N, Chitnis DS. Role of cancer antigen-125 from pleural \& ascitic fluid samples in non malignant conditions. Indian $\mathrm{J}$ Med Res 2007 Jan;125(1):25-30.

24. Sevinc A, Camci C, Turk HM, Buyukberber S. How to interpret serum CA 125 levels in patients with serosal involvement? A clinical dilemma. Oncology 2003;65(1):1-6.

25. Zeillemaker AM, Verbrugh HA, Hoynck van Papendrecht AA, Leguit P. CA 125 secretion by peritoneal mesothelial cells. J Clin Pathol 1994 Mar;47(3):263-265.

26. Bischof P. What do we know about the origin of CA 125? Eur J Obstet Gynecol Reprod Biol 1993 Apr;49(1-2):93-98.

27. Rump A, Morikawa Y, Tanaka M, Minami S, Umesaki N, Takeuchi M, Miyajima A. Binding of ovarian cancer antigen CA125/MUC16 to mesothelin mediates cell adhesion. J Biol Chem 2004 Mar;279(10):9190-9198.

28. Hou W, Sanyal AJ. Ascites: diagnosis and management. Medi Clin North Am 2009 Jul;93(4):801-817.

\section{ABOUT THE AUTHORS}

\section{Mohammed Ali Chowdhury}

Resident, Department of Gastroenterology, Qilu Hospital of Shandong University, Shandong, China

\section{Xiubin Zhang}

Resident, Department of Gastroenterology, Affiliated Hospital of Academy of Medical Sciences of Shandong Province, Jinan, Shandong China

\section{Wei Han (Corresponding Author)}

Professor, Department of Gastroenterology, Qilu Hospital of Shandong University, Shandong, China, Phone: 8613953187653 e-mail: hanwei@sdu.edu.cn 